\title{
ANALISIS EFISIENSI BOILER DENGAN METODE INPUT- OUTPUT DI PT. JAPFA COMFEED INDONESIA Tbk. UNIT BANJARMASIN
}

\author{
Imam Muzaki ${ }^{1)}$, Aqli Mursadin ${ }^{2)}$ \\ ${ }^{1,2}$ Program Studi Teknik Mesin \\ Fakultas Teknik Universitas Lambung Mangkurat \\ JL. Akhmad Yani Km.36 Banjarbaru, Kalimantan Selatan,70714 \\ Telp. 0511-4772646, Fax 0511-4772646 \\ E-mail : imammuzaki4bulan@gmail.com
}

\begin{abstract}
This paper shows some of the research results. The result of this research shows that the boiler efficiency at operational condition (present) is $79,32 \%$ decreased efficiency equal to 9,19\% compared with operational condition with efficiency as big as $88,51 \%$. One of the factors analyzing the declining efficiency of the boiler is greatly influencing the heat transfer process, because if there is dirt or crust on the boiler pipe and the fouling, it will result in the process of heat transfer will decrease so that the heat transfer rate will decrease, and will also affect the amount of heat losses in the boiler.
\end{abstract}

Keywords: palm shell, efficiency, heat rate, commissioning, boiler

\section{PENDAHULUAN}

Industri pada saat ini mengalami kemajuan yang pesat, perkembangan yang terjadi tersebut tentunya akan menimbulkan persaingan yang ketat antara perusahaan, sehingga sangat diperlukan untuk mengkaji ulang kinerja mesin agar tidak terjadi pemborosan energi. Salah satu mesin industri yang perannya sangat penting yaitu boiler. Boiler dalam perusahaan ini merupakan asset yang sangat penting bagi perusahaan, yang yang menghasilkan output berupa uap (steam), digunakan untuk mengepress pakan ternak pada proses produksi. Apabila terjadi masalah pada sisitem boiler, maka kelancaran steam (uap) akan terganggu sehingga produksi pakan ternak akan mengalami penurunan.

Penelitian ini menerangkan hasil analisa efisiensi boiler berkapsitan 4 ton/jam untuk mengetahui efisiensi boiler pada kondisi komisioning dengan kondisi operasional (sekarang) di PT Japfa Comfeed Indonesia Tbk, Unit Banjarmasin.

Boiler adalah sebuah ketel uap yang tertutup serta panas pembakaran diteruskan ke air, sampai menjadi air yang beruap panas atau steam. Setelah itu uap panas tersebut dalam tekanan, yang dimanfaatkan untuk suatu proses industri. (Djokosetyardjo, 2003). Sistem ketel uap ini terdiri dari beberapa bagian yaitu, sistem air bahan bakar, sistem uap panas dan sistem feed water. Sistem bahan bakar merupakan seluruh sistem keperluan untuk memanaskan sebuah ketel uap sedangkan peralatan bahan bakar tergantung pada jenis bahan bakar tersebut. Sistem feed water (air umpan) merupakan sistem boiler yang menyuplai segala keperluar air kedalam drum boiler. Sistem uap panas / steam merupakan sistem yang menampung kebutuhan steam dan mengontrolnya sesui kebutuhan produksi, serta mengatur tekanan steam sesuai keperluan produksi. 
Boiler terdiri dari 2 komponen utama, yaitu :

1. Furnace (ruang bakar) sebagai alat untuk mengubah energi kimia menjadi energi panas.

2. Steam Drum yang mengubah energi pembakaran (energi panas) menjadi energi potensial steam (energi panas).

Boiler pada dasarnya terdiri dari drum yang tertutup ujung dan pangkalnya dan dalam perkembangannya dilengkapi dengan pipa api maupun pipa air. Banyak orang yang mengklasifikasikan ketel steam tergantung kepada sudut pandang masing - masing.

Syarat - syarat boiler yang ideal, yaitu:

1. Dapat menghasilkan jumlah uap yang maksimum dengan jumlah bahan bakar yang minimum.

2. Kapasitas uap dan tekanan kerja harus konstan.

3. Perangkat pembakaran mampu membakar unsur-unsur bahan bakar secara sempurna sehingga di dapat hasil yang optimal.

4. Sirkulasi air harus baik agar diperoleh suhu yang merata pada seluruh bagian ketel, maka penyerapan kalor oleh air lebih efektif.

5. Konstruksi ketel sederhana, sehingga biaya pembuatan, operasi dan perawatan lebih ekonomis dan hemat tempat.

6. Alat-alat perlengkapan ketel harus berfungsi dengan baik sehingga ketel dapat beroperasi dengan baik dan aman.

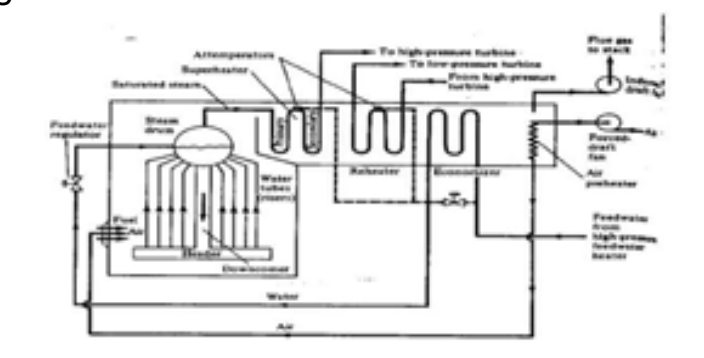

Gambar 1. Diagram Alir Boiler

Seiring dengan perkembangan teknologi dan evaluasi dari produk boiler berdasarkan nilai emisi gas buang yang mencemari lingkungan, maka berikut klasifikasi boiler berdasarkan fluida yang mengalir, yaitu:

a. Fire tube boiler (ketel pipa api)

Boiler pipa api merupakan pengembangan dari ketel lorong api dengan menambah pemasangan pipa -pipa api, dimana gas panas hasil pembakaran dariruang bakar mengalir didalamnya, sehingga akan memanasi dan menguapkan air yang berada di sekeliling pipa - pipa api tersebut. Pipa - pipa api berada atau terendam didalam air yang akan diuapkan. Volume air kira - kira 3/4 dari tangki ketel. Jumlah pass dari boiler tergantung dari jumlah laluan vertikal dari pembakaran diantara furnace dan pipa -pipa api. Laluan gas pembakaran pada furnace dihitung sebagai pass pertama boiler jenis ini banyak dipakai untuk industri pengolahan mulai skala kecil sampai skala menengah. 
Contoh boiler pipa api ditunjukkan dalam Gambar 2 dan Gambar 3 serta cara kerja boiler pipa api ditunjukkan dalam Gambar 4.
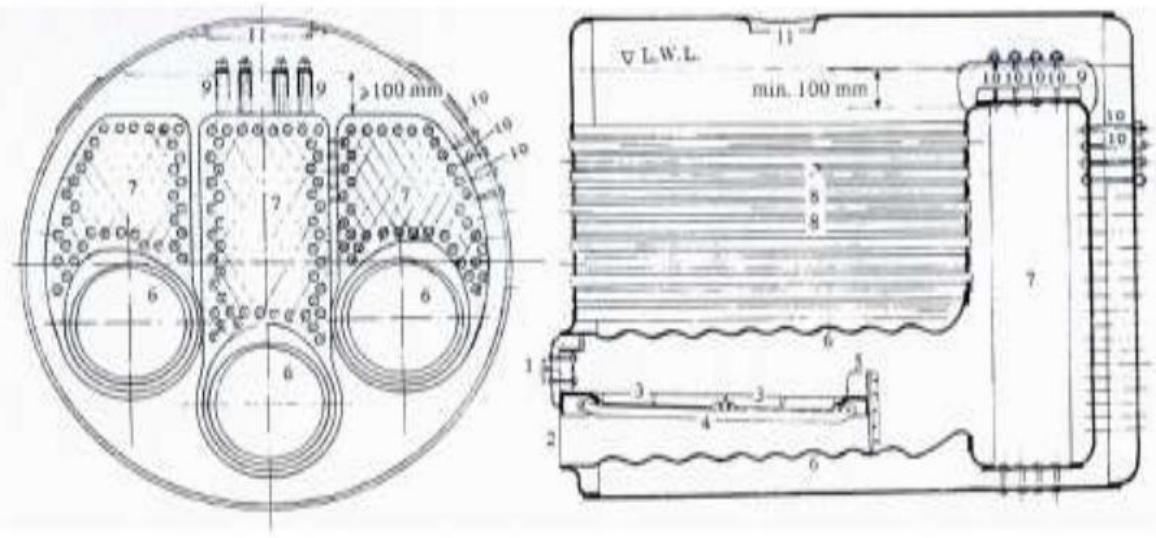

Gambar 2. Boiler Scocth

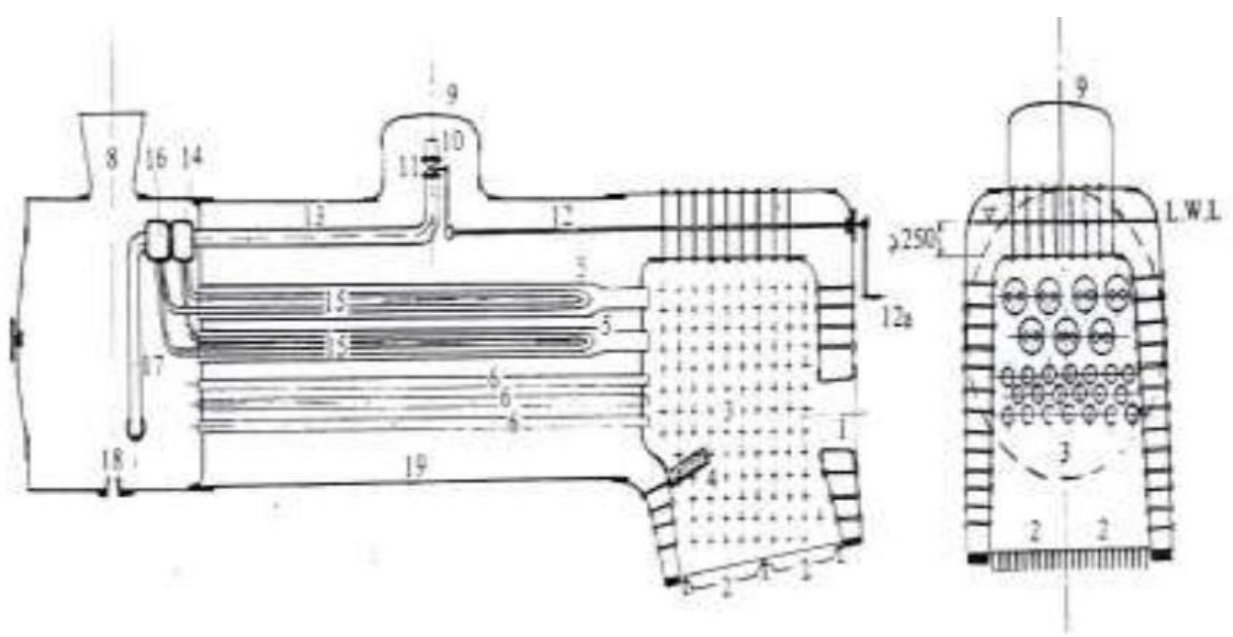

Gambar 3. Boiler Lokomotif

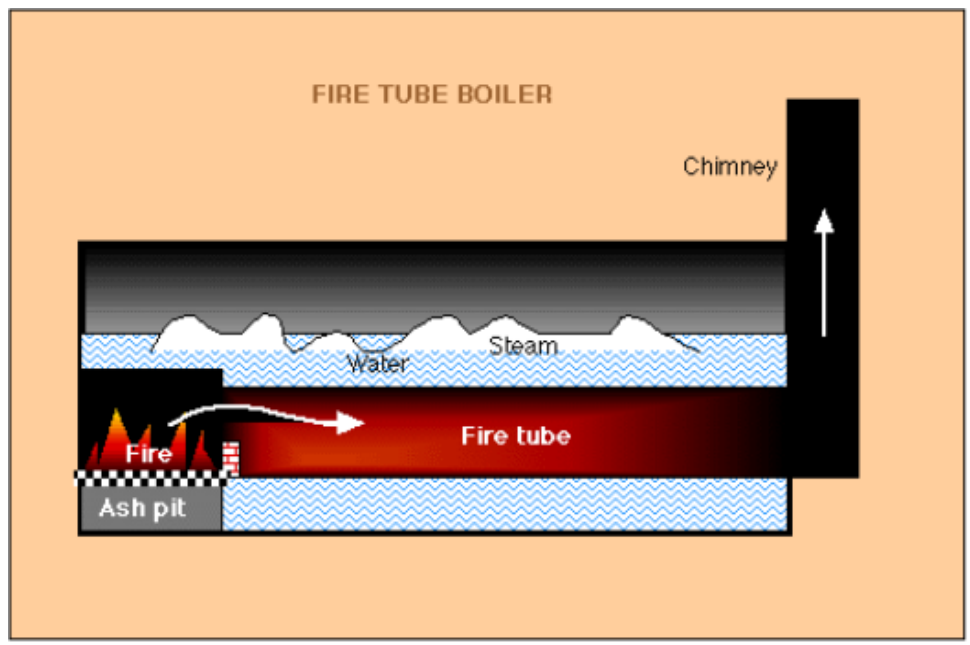

Gambar 4. Cara Kerja Fire Tube Boiler (Ketel Pipa Api) 
Keuntungan boiler pipa api, yaitu:

1. Tidak membutuhkan air isian boiler dengan kualitas yang tinggi.

2. Konstruksi sederhana sehingga perawatan lebih mudah.

3. Endapan lumpur lebih mudah dibersihkan.

Kelemahan boiler pipa api, yaitu:

1. Pemanasan awal membutuhkan waktu lama.

2. Tekanan uap yang dihasilkan rendah.

3. Kapasitas uap yang dihasilkan kecil.

b. Water tube boiler (ketel pipa air)

Pada Ketel pipa air seperti tampak pada Gambar 3, air umpan boiler mengalir melalui pipa-pipa masuk kedalam drum. Air yang tersirkulasi dipanaskan oleh gas pembakaran membentuk steam pada daerah uap dalam drum. Ketel ini dipilih jika kebutuhan steam dan tekanan steam sangat tinggi seperti pada kasus ketel untuk pembangkit tenaga listrik.Untuk ketel pipa air yang menggunakan bahan bakar padat, tidak umum dirancang secara paket. Karakteristik ketel pipa air sebagai berikut:

1. Force, induce dan balance draft membantu untuk meningkatkan effisiensi.

2. Kurang toleran terhadap kualitas air yang dihasilkan dari pengolahan air.

3. Memungkinkan untuk tingkat effisiensi panas yang lebih tinggi.

Keuntungan boiler pipa air, yaitu:

1. Sanggup bekerja dengan tekanan tinggi.

2. Berat boiler yang relatif ringan.

3. Kapasitas yang besar.

4. Dapat dioperasikan dengan cepat, jadi dalam waktu yang singkat telah dapat memproduksi uap.

Kelemahan dari boiler pipa air, yaitu:

1. Kontruksi boiler sudah tidak sederhana lagi, sehingga perawatan lebih sulit dilakukan.

2. Menuntut air isian harus selalu bersih, agar tidak tejadi pembentukan batu ketel.

3. Perencanaan lebih sulit sehingga harganya mahal.

Contoh boiler pipa air ditunjukkan dalam Gambar 5 dan Gambar 6 serta cara kerja boiler pipa api ditunjukkan dalam Gambar 7. 


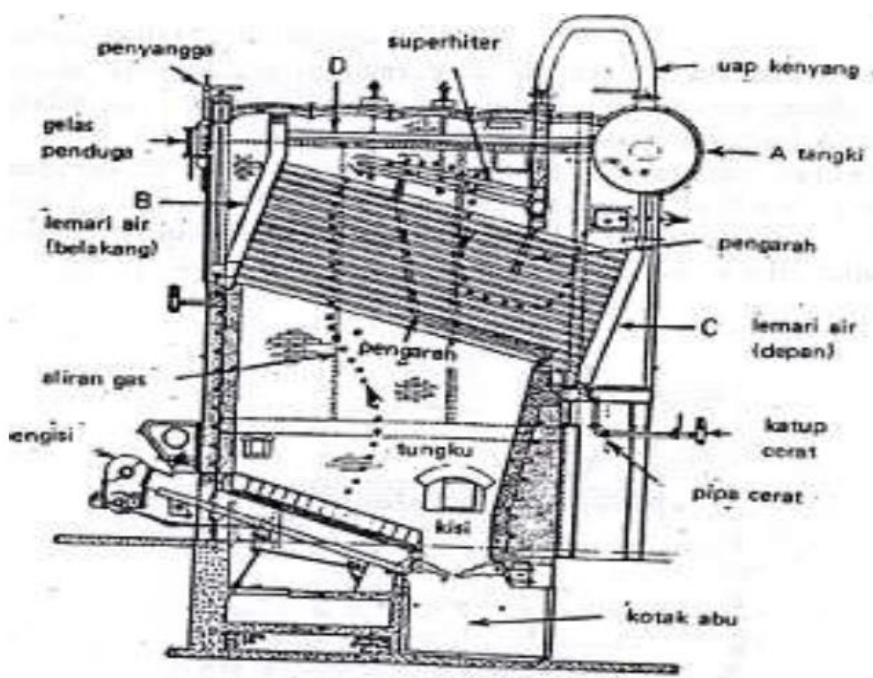

Gambar 5. Boiler Babcock \& Wilcox

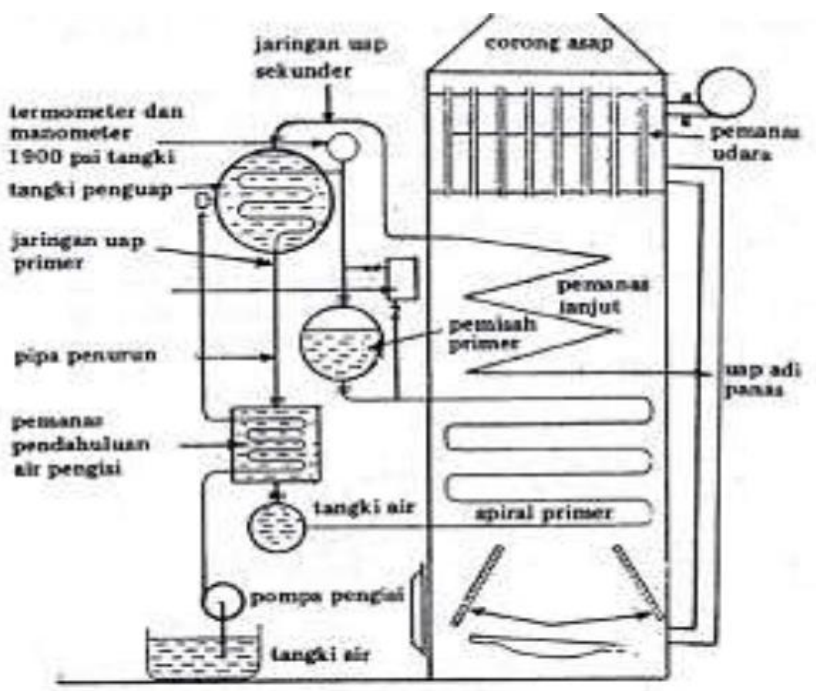

Gambar 6. Boiler Benson

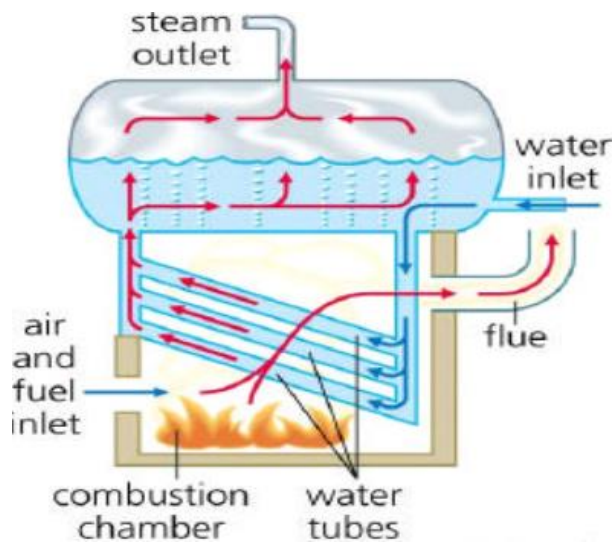

Gambar 7. Cara Kerja Water Tube Boiler (Ketel Pipa Air) 
Efisiensi merupakan barometer kinerja suatu mesin. Pengertian efisiensi mesin ketel uap, yaitu nilai tingkat kemampuan kinerja boiler yang didapat dari perbandingan antara energi keluaran (output) dengan energi yang masuk (input).

Metodelogi ini sering kali disebut sebagai metode langsung / input - output karena nilai efisiensinya didapat dari pembagian antara keluaran / output (steam) dengan panas masuk / input (bahan bakar). Sehingga didapat rumus efisiensi boiler, yaitu:

Efisiensi Boiler $=\frac{\text { panas keluar }}{\text { panas masuk }} \times 100 \%$

$\eta$ Boiler $=\frac{Q(h g-h f)}{q \times G C V} \times 100 \%$

\section{Keterangan:}

$\mathrm{Q} \quad=$ Jumlah hasil steam $(\mathrm{kg} / \mathrm{jam})$.

$\mathrm{q} \quad=$ Jumlah konsumsi bahan bakar (kg/jam).

$\mathrm{h}_{\mathrm{g}} \quad=$ Enthalpy steam jenuh (kkal/kg).

$\mathrm{h}_{\mathrm{f}} \quad=$ Enthalpy air umpan $(\mathrm{kkal} / \mathrm{kg})$.

GCV = Nilai panas kotor bahan bakar (kkal/kg) (Unep 2006).

\section{METODE PENELITIAN}

Tempat dan Jadwal Penelitian. Tempat penelitian dilakukan di PT. Japfa Comfeed Indonesia Tbk,Unit Banjarmasin. Data yang diperoleh merupakan data operasi PT. Japfa Comfeed Indonesia Tbk, Unit Banjarmasin yang diambil dari system panel control room, selama 1 bulan pada saat komisioning (04 februari 02 maret 2008), dan satu bulan pada kondisi operasional (04 September 29 September 2017).

Metodologi penelitian yang dilakukan adalah:

\section{a. Studi Literatur}

Dasar teori - teori maupun konsep - konsep dalam penelitian yang ada kaitanya dengan penelitian yang akan dilakukan. Studi pustaka yang diteliti mengenai boiler dari sumber beberapa buku, yang ada di PT JAPFA maupun e-book dan jurnal internet.

b. Pengumpulan data

Merupakan cara untuk mendapatkan data yang diperlukaan yang digunakan penulis dalam skripsi, yang melalui beberapa metode, antara lain:

1) Metode Observasi

Merupakan metode yang digunakan untuk mendapatkan data yang didapat langsung dari objek yang diteliti. Sehingga mendapatkan data yang diperlukan.

2) Metode Interview

Suatu metode pengumpulan data melalui wawancara atau tanya jawab secara langsung dari pihak pekerja instansi / perusahaan untuk memperoleh data-data yang diperlukan.

3) Riset Pustaka

Pengumpulan sebuah data yang didapatkan melalui beberapa referensi 
buku diberbagai tempat dan sumber-sumber yang ada kaitannya dengan objek yang diteliti yang nantinya berguna untuk mengembangkan hasil observasi dan interview.

Data penelitian ini terbagi dua yaitu:

1. Data Primer

Sebuah data yang didapatkan ditempat penelitian, PT. Japfa Comfeed Indonesia Tbk,Unit Banjarmasin. Seperti: spesifikasi boiler, temperatur feed water, tekanan steam, temperatur steam, konsumsi bahan bakar, dan jumlah steam dan nilai kalor bahan bakar.

2. Data sekunder

Sebuah data yang didapatkan dari sumber pustaka - pustaka yang mendukung penelitian. Seperti : Chemicalogic Steam Tab Companion dan proximate analisis.

3. Pengolahan dan Analisis Data

Pengolahan sebuah data yang sudah didapatkan kemudian diolah dan dianalisa dengan mengacu pada dasar teori dan tujuan penelitian.

4. Pengambilan Kesimpulan

Dari hasil analisa yang didapat selanjutnya dapat diambil kesimpulan mengenai analisa efisiensi boiler pada kondisi komisioning dan kondisi operasional PT Japfa Comfeed Indonesia Tbk, Unit Banjarmasin Tbk. (PT. Japfa).

Diagram alir penelitian ini dapat di lihat dalam Gambar 8.

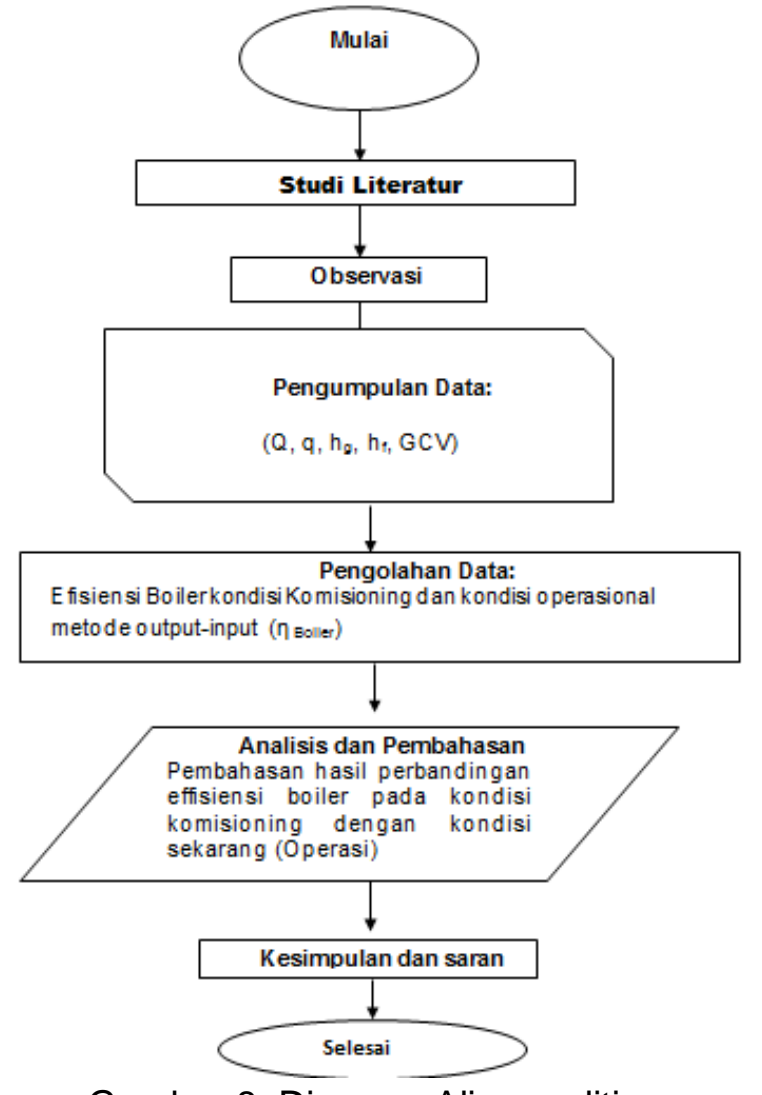

Gambar 8. Diagram Alir penelitian 


\section{PEMBAHASAN}

Analisis Perhitungan, Contoh perhitungan efisiensi boiler dengan metode output - input pada kondisi komisioning.

Diketahui :

$$
\begin{array}{ll}
\mathrm{Q} & =1416,667(\mathrm{Kkl} / \mathrm{jam}) \\
\mathrm{q} & =235(\mathrm{Kkl} / \mathrm{jam}) . \\
\mathrm{P} \text { steam } & =8,9260 \mathrm{bar} \\
\mathrm{t} \text { steam } & =175 \mathrm{oC} \\
\mathrm{t} \mathrm{fw} & =50 \mathrm{oC} \\
\mathrm{GCV} & =4150(\mathrm{Kkal} / \mathrm{kg}) .
\end{array}
$$

Untuk mencari enthalpy steam, dan enthalpy feed dengan menggunakan software chemicallogic steamtab companion, maka diperoleh : $h_{g}=2772,71 \mathrm{kj} / \mathrm{kg}$ dan $h_{f}=209,342(\mathrm{~kJ} / \mathrm{kg})$.

Kemudian di konversikan dari Kilo Joule $(\mathrm{kJ} / \mathrm{kg})$ ke kilo kalori $(\mathrm{Kkl} / \mathrm{kg})$

$\mathrm{h}_{\mathrm{g}}=2772,71(\mathrm{~kJ} / \mathrm{kg})=662,4(\mathrm{kkal} / \mathrm{kg})$

$\mathrm{h}_{\mathrm{f}}=209,342(\mathrm{~kJ} / \mathrm{kg})=50,012(\mathrm{kkal} / \mathrm{kg})$

$$
\begin{aligned}
\eta \text { Boiler } & =\frac{1416,667 \times(662,4-50,012)}{235 \times 4150} \times 100 \% \\
& =88,91 \%
\end{aligned}
$$

Dari hasil perhitungan efisiensi boiler pada kondisi operasional diperoleh grafik dibawah ini.

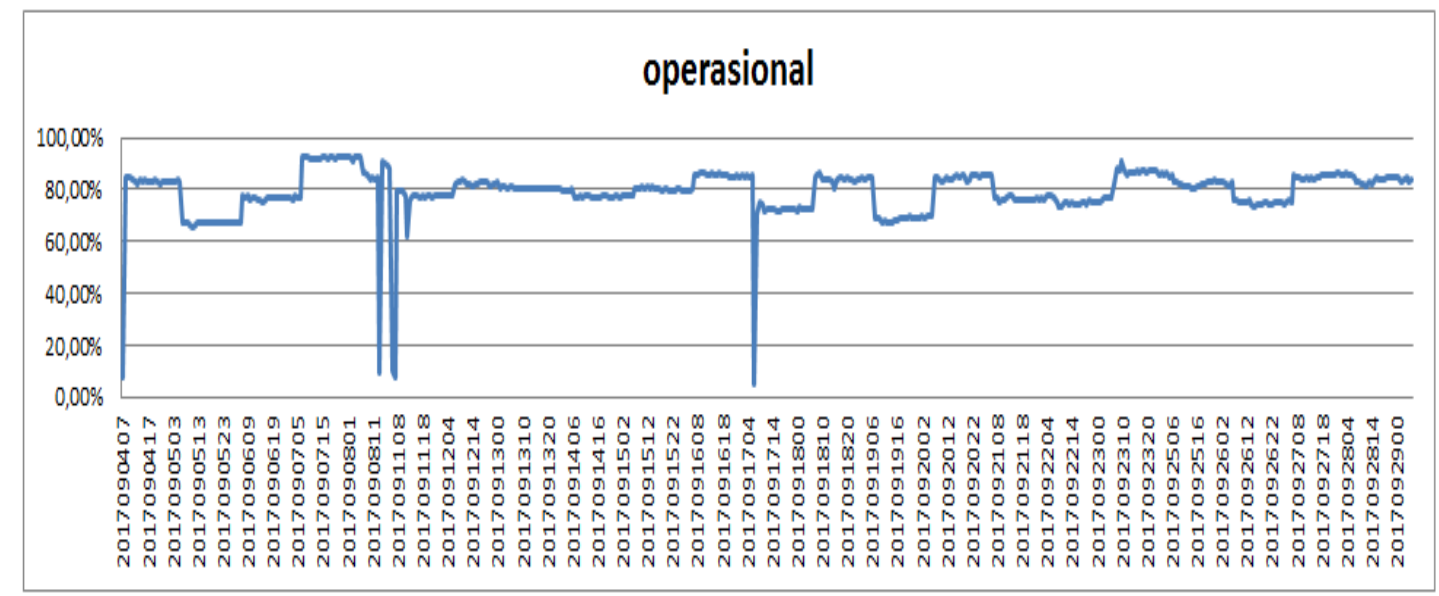

Gambar 9. Grafik Efisiensi Boiler Kondisi Operasional

Dari Gambar 9 dapat dilihat fluktuasi efisiensi boiler pada kondisi operasional adalah tidak menetap dan terjadi lonjakan. Nilai efisiensi boiler rata - rata pada kondisi operasional adalah 79,32 \%, nilai tertinggi tercapai pada, tanggal 07 September 2018 sebesar 92,76\%, hal ini terjadi karena pada tanggal tersebut permintaan produksi komersil yang besar, sehingga boiler dalam kondisi beban puncak, sehingga efisiensi boiler menjadi meningkat. Serta efisiensi terendah tercapai pada tanggal 11 September 2018 tepatnya pada jam 12.00 sebesar $61,73 \%$, menurunya efisiensi boiler tersebut dikarenakan permintaan produksi yang kecil, sehingga boiler memproduksi steampun sedikit dan boiler hanya untuk 
memenuhi steam, ketika sudah steam tercapai maka boiler berhenti sejenak, inilah yang mempengaruhi menurunya efisiensi boiler. Sedangkan efisiensi boiler sebesar 5,34\%, terjadi pada tanggal 07 September 2018 tepatnya pada jam 07.00 wita, dikarenakan pada tanggal dan waktu tersebut ketika start awal boiler dioperasikan, setelah berhenti produksi selama selama 2 (dua) hari.

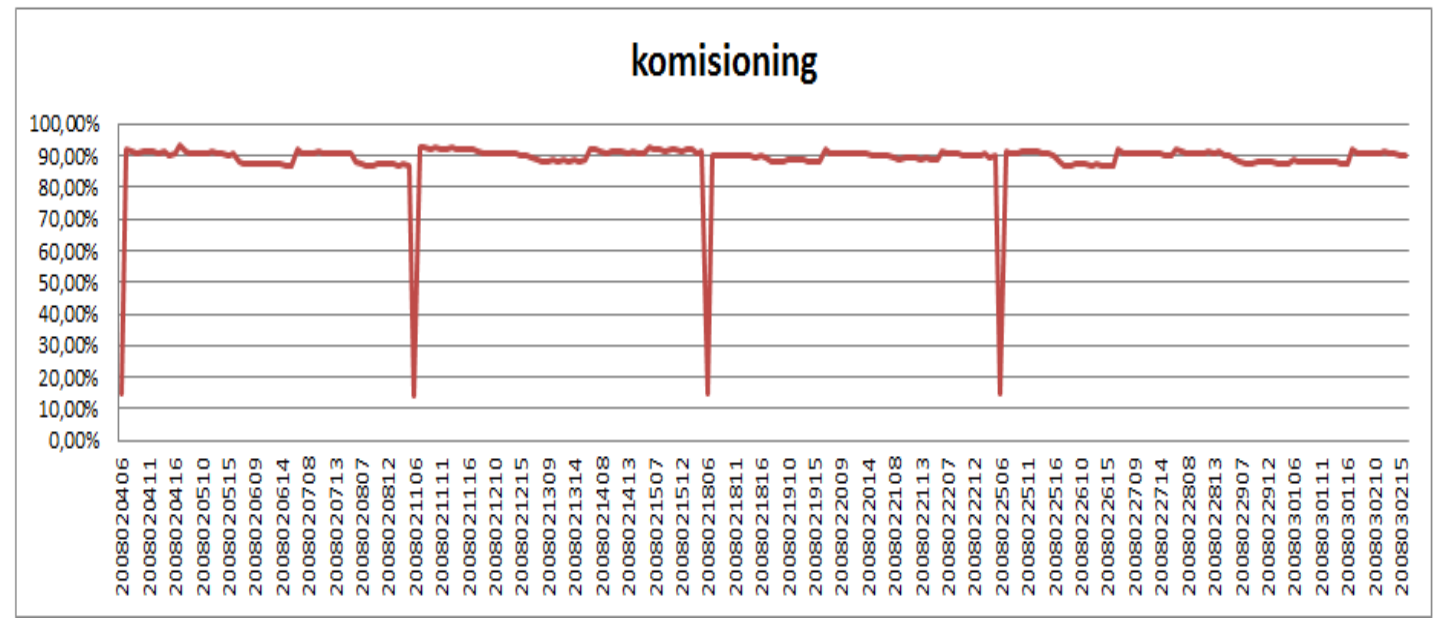

Gambar 10. Grafik efisiensi boiler kondisi komisioning

Dari Gambar 10 dapat dilihat fluktuasi efisiensi boiler pada kondisi komisioning adalah cenderung tetap. Nilai efisiensi boiler rata - rata pada kondisi komisioning adalah 88,51\%, nilai tertinggi tercapai pada tanggal 11 februari 2008 sebesar $93,27 \%$ pada saat boiler stabil beroperasi dalam kondisi performa yang maksimal, dengan permintaan produksi yang besar. Efisiensi terendah tercapai pada tanggal 26 februari 2008 sebesar 86,44 \%, ketika boiler stabil beroperasi kondisi performa yang maksimal, dan permintaan produksi yang lebih kecil dibandingkan pada tanggal 11 februari 2008. Sedangkan turunya efisiensi boiler pada gambar sebesar $14,20 \%$ ini, pada saat boiler mulai dioperasikan setelah berhenti produksi selama 2 (dua) hari.

Dari perbandingan nilai rata-rata efisiensi boiler pada perhitungan efisiensi dapat diketahui nilai rata - rata efisiensi boiler pada saat komisioning sebesar 88,51 $\%$ dan nilai rata - rata efisiensi boiler kondisi operasional sebesar 79,32 \% terjadi penurunan efisiensi boiler sebesar 9,19\%. Salah satu analisa faktor menurunya efisiensi boiler adalah disebabkan oleh faktor kebersihan dari permukaan pipa pada boiler, sangat berpengaruh terhadap proses perpindahan panas / heat transfer, karena apabila adanya kotoran maupun kerak pada pipa boiler dan pengendapan (fouling), akan berakibat pada proses perpindahan panas / heat transfer akan berkurang sehingga laju perpindahan panaspun akan menurun, dan juga akan berpengaruh terhadap tingginya nilai temperatur gas buang yang mempengaruhi besarnya kerugian - kerugian panas lainya pada boiler. 


\section{KESIMPULAN}

Berdasarkan hasil analisis efisiensi boiler pada kondisi komisioning dengan kondisi operasional (sekarang) di PT Japfa Comfeed Indonesia Tbk, Unit Banjarmasin masing-masing sebesar $88,51 \%$ dan $79,32 \%$, mengalami penurunan efisiensi sebesar $9,19 \%$. Salah satu faktor penyebabnya, yaitu kebersihan dari permukaan tube pada boiler.

\section{DAFTAR PUSTAKA}

Djokosetyardjo, IR. M. J, 2003, Ketel Uap, Cetakan Kelima, Pradnya Paramita. Jakarta.

El-Wakil, M.M. 1985. Power Plant Techology. New York:McGraw-Hill Book.

Gaol , D. P., L. 2015. Analisa Efisiensi Water Tube Boiler Berbahan Bakar Fiber, Cangkang Sawit Dan Kulit Kayu Menggunakan Metode Langsung. Skripsi. Universitas Sumatera Utara. Medan.

UNEP. 2006. Peralatan Energi Panas Boiler \& Pemanas Fluida Thermis, Pedoman Efisiensi Energi Untuk Industri Di Asia.

http://www.indobioethanol.com diakses pada 27 Februari 2015. 